\title{
Management of oral anticoagulation after cardioembolic stroke and stroke survival data from a population based stroke registry (LuSSt)
}

\author{
Frederick Palm ${ }^{1 * \dagger}$, Martin Kraus ${ }^{2+}$, Anton Safer ${ }^{3}$, Joachim Wolf ${ }^{1}$, Heiko Becher ${ }^{3}$ and Armin J Grau ${ }^{1}$
}

\begin{abstract}
Background: Cardioembolic stroke (CES) due to atrial fibrillation (AF) is associated with high stroke mortality. Oral anticoagulation (OAC) reduces stroke mortality, however, the impact of OAC-administration during hospital stay post ischemic stroke on mortality is unclear. We determined whether the timing of OAC initiation among other prognostic factors influenced mortality after CES.

Methods: Within the Ludwigshafen Stroke Study (LuSSt), a prospective population-based stroke register, we analysed all patients with a first ever ischemic stroke or TIA due to AF from 2006 until 2010. We analysed whether treatment or non-treatment with OAC and initiation of OAC-therapy during and after hospitalization influenced stroke mortality within 500 days after stroke/TIA due to AF.

Results: In total 479 patients had a first-ever ischemic stroke $(n=394)$ or TIA $(n=85)$ due to AF. One-year mortality rate was $28.4 \%$. Overall, 252 patients (52.6\%) received OAC. In 181 patients (37.8\%), OAC treatment was started in hospital and continued thereafter. Recommendation to start OAC post discharge was given in 110 patients (23.0\%) of whom 71 patients received OAC with VKA (14.8\%). No OAC-recommendation was given in 158 patients (33.0\%). In multivariate Cox regression analysis, higher age (HR 1.04; 95\% Cl 1.02-1.07), coronary artery disease ( $\mathrm{HR}: 1.6 ; 95 \% \mathrm{Cl}$ 1.1-2.3), higher mRS-score at discharge (HR 1.24; 95\% Cl 1.09-1.4), and OAC treatment ((no OAC vs started in hospital (HR: 5.4; 95\% Cl 2.8-10.5), were independently associated with stroke mortality. OAC-timing did not significantly influence stroke mortality (started post discharge vs. started in hospital (HR 0.3; 95\% Cl 0.07-1.4)).

Conclusions: OAC non-treatment is the main predictor for stroke mortality. Although OAC initiation during hospital stay showed a trend towards higher mortality, early initiation in selected patients is an option as recommendation to start OAC post hospital was implemented in only $64.5 \%$. This rate might be elevated by implementation of special intervention programs.
\end{abstract}

Keywords: Oral anticoagulation, Cardioembolic stroke, Atrial fibrillation

\section{Background}

Atrial fibrillation (AF) is the main cause of cardioembolic stroke (CES), the dominant ischemic stroke subtype in the elderly [1,2]. Additionally, non-diagnosed AF is likely to be responsible for many cryptogenic strokes [3]. Prevalence of AF increases with age and lifetime risk of developing AF is estimated to be $25 \%$ after reaching the age of 40 [4]. Due to demographic changes in industrial countries,

\footnotetext{
* Correspondence: palmf@klilu.de

${ }^{\dagger}$ Equal contributors

'Department of Neurology, Städtisches Klinikum Ludwigshafen, Bremserstr.

79, 67063 Ludwigshafen, Germany

Full list of author information is available at the end of the article
}

prevalence of $\mathrm{AF}$ is predicted to increase in the future [5]. Concomitant to the incidence of AF, incidence of CES is likely to increase. CES is associated with higher stroke severity and mortality [6,7]. Stroke recurrence is associated with much worse outcome [6,7]. Early stroke recurrence is frequent in ischemic stroke due to large artery atherosclerosis [8], in contrast, it is less common in CES $[8,6]$. However, recurrence risk of CES is highest among stroke subtypes in the long term [7]. Oral anticoagulation (OAC) with vitamin $\mathrm{K}$ antagonists (VKA) and new oral anticoagulants (NOAC) is effective in primary and secondary stroke prevention and in reducing mortality $[9,10]$. Both,

\section{Ciomed Central}

(c) 2014 Palm et al.; licensee BioMed Central Ltd. This is an Open Access article distributed under the terms of the Creative Commons Attribution License (http://creativecommons.org/licenses/by/4.0), which permits unrestricted use, distribution, and reproduction in any medium, provided the original work is properly credited. The Creative Commons Public Domain Dedication waiver (http://creativecommons.org/publicdomain/zero/1.0/) applies to the data made available in this article, unless otherwise stated. 
VKAs and NOACs increase risk of intracerebral hemorrhage (ICH) [11]. As early hemorrhagic transformation occurs in CES in up to $17 \%$ within 5 days [12], and occurence of $\mathrm{ICH}$ is reported to be up to $12 \%$ [13], timing of OAC initiation after acute CES is still a controversial issue and its impact on mortality is not clear.

We hypothesized that initiation of OAC in hospital after first-ever CES is associated with a significant reduction on mortality compared to OAC non-treatment and $\mathrm{OAC}$ initiation post discharge. Implementation of OAC recommendation was additionally analysed.

\section{Methods}

The "Ludwigshafen Stroke Study" (LuSSt) is a populationbased, prospective registry of stroke and transient ischemic attack (TIA) in the City of Ludwigshafen (Germany), starting January 1st, 2006. A detailed description of LuSSt has been published recently [14]. All patients with first-ever ischemic strokes (FEIS) due to AF until December 31st, 2010 were included in the present analysis.

\section{Summary of study population, case ascertainment follow-up and standard definitions}

Ludwigshafen is an industrial city in the state of RhinelandPalatinate in Western Germany. The total source population was 167,657 inhabitants $(83,009$ males and 84,648 females) on December 31st, 2008, which was the midpoint of the study period. Multiple overlapping methods of patient identification were used in order to achieve complete case ascertainment as described before [14]. Collaboration with all hospitals in Ludwigshafen and surrounding hospitals treating stroke patients outside the city boundaries ensured complete case acquisition. Patients who have been treated in other hospitals, hospitals abroad and non-hospitalized patients were identified by contacting all general practitioners, specialists in internal medicine and neurologists practicing in Ludwigshafen. In addition nursing and residential homes were contacted regularly. In case of identified stroke patients via death certificate, patients' general practitioner was contacted in order to achieve more information, especially with regards to stroke symptoms, current stroke and antithrombotic treatment. Follow up investigations were conducted by telephone 28 days, 3,12 and 36 months after stroke onset, using a standardised questionnaire, if written informed had been given by patients or their legal representatives. Information about survival was collected by population registration authority in all patients without statement of consent, or if patients could not be contacted. The study (LuSSt) was approved by the ethics committee of "Landesärztekammer Rhineland-Palatinate" (reference number: 837.333.05) and the local data protection commissioner of Rhineland-Palatinate. Stroke was defined according to the definition of the World Health Organization (WHO) [15]. Stroke subtype classification was based on the results of brain imaging, discriminating between ischemic stroke (IS), intracerebral hemorrhage $(\mathrm{ICH})$ or subarachnoid hemorrhage (SAH). Patients with no clinical evidence of any previous stroke event were diagnosed as first-ever stroke (FES) irrespective of brain imaging. Assignment to etiology in ischemic stroke was performed using modified TOAST-criteria and has been described in detail before [2]. TIA was defined as a transient focal cerebral ischemia with symptoms lasting < 24 hours independent of neuroimaging results. Due to current changes in the definition of TIA by usage of MRI imaging, we included patients with both, IS and TIA. All patients admitted to the Klinikum Ludwigshafen received intensive diagnostic workup as previously described [2]. About $90 \%$ of all patients with FES in the source population are admitted to this hospital.

\section{Neuroradiological findings, risk factors, risk stratification scores and stroke severity}

Neuroradiological findings were categorized as territorial infarction (TI), lacunar infarction (LI), hemorrhagic transformation (HT) including hemorrhagic infarction, defined as petechial bleeding in the infarction area, and parenchymal hematoma as hematoma in the infarcted area with a space-occupying effect or a traumatic subarachnoid hemorrhage (SAH) due to ischemic infarction [12]. Hemorrhagic transformation was detected in CT/MRI performed on admission or in repeated CT/ MRI performed during hospital stay. Cardiovascular risk factors were defined according to current national and international guidelines as recently described in detail [2]. AF (known or new diagnosis) was defined with current ESC guidelines as irregular RR intervals with a variable atrial cycle length and absent $P$ waves in the surface ECG [16]. Other sources of cardiac embolism have been ruled out by using transthoracic or transesophageal echocardiography. The $\mathrm{CHA}_{2} \mathrm{DS}_{2}$-VASc and HASBLED-Score were used as risk stratification tools to evaluate stroke and bleeding risk [17]. Stroke severity was analysed using the National Institute of Health Stroke Scale (NIHSS) on admission and modified Rankin-Scale (mRS) on discharge by experienced neurologists of the study team $[18,19]$. The glomerular filtration rate was determined on admission using Modification of Diet in Renal Disease (MDRD) formula [20].

\section{Antithrombotic treatment}

Prestroke treatment with VKA (=oral anticoagulation) and antiplatelet agents was assessed. In patients receiving VKA, international normalized ratio (INR) was determined on admission. Poststroke management was subdivided as follows: 1 . No OAC (neither given nor recommended and $\mathrm{OAC}$ recommended but not given post hospital stay); 2. OAC started in hospital; 3. OAC started 
Table 1 Baseline characteristics of 479 patients with AF-associated FE-IS and TIA (neuroimaging, stroke severity and risk stratification scores)

\begin{tabular}{|c|c|c|c|c|c|}
\hline \multicolumn{2}{|l|}{ Variable $\left(\mathrm{N}^{*}\right)$} & \multirow[t]{2}{*}{ Death within 500 days } & \multirow[t]{2}{*}{ Survival at $\mathbf{5 0 0}$ days } & \multirow[t]{2}{*}{$\mathrm{p}$-value univariate } & \multirow[t]{2}{*}{ p-value multivariate } \\
\hline & N (\%) & & & & \\
\hline \multicolumn{2}{|l|}{ Gender $\left(479^{*} / 479\right)$} & & & $p=0.31$ & \\
\hline Male & $197(41.1 \%)$ & $55(27.9 \%)$ & $142(72.1 \%)$ & & \\
\hline Female & $282(58.9 \%)$ & $92(32.6 \%)$ & $190(67.4 \%)$ & & \\
\hline \multicolumn{2}{|l|}{ Age (years) $\left(479^{*} / 479\right)$} & & & $\mathrm{p}<0.0001$ & $p=0.001$ \\
\hline $20-65$ & $44(9.2 \%)$ & $3(6.8 \%)$ & $41(93.2 \%)$ & & \\
\hline $66-75$ & $105(21.9 \%)$ & $18(17.1 \%)$ & $87(82.9 \%)$ & & \\
\hline $76-85$ & $204(42.6 \%)$ & $56(27.5 \%)$ & $148(72.6 \%)$ & & \\
\hline$>85$ & $126(26.3 \%)$ & $70(55.6 \%)$ & $56(44.4 \%)$ & & \\
\hline \multicolumn{2}{|l|}{ Diagnosis $(479 * / 479)$} & & & $p=0.0001$ & $p=0.95$ \\
\hline Ischemic stroke & $394(82.3 \%)$ & $135(34.3 \%)$ & $259(65.7 \%)$ & & \\
\hline TIA & $85(17.7 \%)$ & $12(14.1 \%)$ & $73(85.9 \%)$ & & \\
\hline \multicolumn{6}{|c|}{ Neuroradiological Findings $\left(476^{*} / 479\right)$} \\
\hline Territorial infarction (recent) & $256(53.8 \%)$ & 99 (38.7\%) & $157(61.3 \%)$ & $\mathrm{p}<0.0001$ & $p=0.055$ \\
\hline Territorial infarction (old) & $45(9.5 \%)$ & $15(33.3 \%)$ & $30(66.7 \%)$ & $p=0.61$ & \\
\hline Hemorrhagic transformation & $26(5.5 \%)$ & $14(53.8 \%)$ & $12(46.2 \%)$ & $p=0.01$ & $p=0.46$ \\
\hline Hemorrhagic infarction & $15(57.7 \%)$ & $7(46.7 \%)$ & $8(53.3 \%)$ & & \\
\hline Parenchymal haematoma & $8(30.8 \%)$ & $6(75 \%)$ & $2(25 \%)$ & & \\
\hline Subarachnoidal hemmorh. & $3(11.5 \%)$ & 1 (33.3\%) & $2(66.7 \%)$ & & \\
\hline \multicolumn{6}{|l|}{ Stroke severity } \\
\hline \multicolumn{2}{|c|}{ NIHSS at admission $\left(461^{*} / 479\right)$} & & & $p<0.0001$ & $\mathrm{p}=0.8$ \\
\hline $0-3$ & $227(49.2 \%)$ & $38(16.7 \%)$ & $189(83.3 \%)$ & & \\
\hline $4-8$ & $117(25.4 \%)$ & $39(33.3 \%)$ & $78(66.7 \%)$ & & \\
\hline$>9$ & $117(25.4 \%)$ & $62(53 \%)$ & $55(47 \%)$ & & \\
\hline \multicolumn{2}{|l|}{$m R S$ at discharge $\left(470^{*} / 479\right)$} & & & $p<0.0001$ & $p=0.0007$ \\
\hline $0-1$ & $197(41.9 \%)$ & $23(11.7 \%)$ & $174(88.3 \%)$ & & \\
\hline $2-3$ & $123(26.2 \%)$ & $38(30.9 \%)$ & $85(69.1 \%)$ & & \\
\hline$>4$ & $150(31.9 \%)$ & $85(56.7 \%)$ & $65(43.3 \%)$ & & \\
\hline \multicolumn{6}{|l|}{ Risk stratification score } \\
\hline \multicolumn{2}{|c|}{$\mathrm{CHA}_{2} \mathrm{DS}_{2}$-Vasc-Score $(452 * / 479)$} & & & $p=0.0003$ & \\
\hline $2-4$ & $30(6.6 \%)$ & $2(6.7 \%)$ & $28(93.3 \%)$ & & \\
\hline 5 & $93(20.6 \%)$ & $23(24.7)$ & $70(75.3 \%)$ & & \\
\hline 6 & 159 (35.2\%) & $42(26.4 \%)$ & $117(73.6 \%)$ & & \\
\hline 7 & $95(21 \%)$ & $31(32.6 \%)$ & $64(67.4 \%)$ & & \\
\hline $8-9$ & $75(16.6 \%)$ & $35(46.7 \%)$ & $40(53.3 \%)$ & & \\
\hline \multicolumn{2}{|l|}{ HASBLED-Score $\left(458^{*} / 479\right)$} & & & $\mathrm{p}<0.0001$ & \\
\hline $0-2$ & $115(25.1 \%)$ & $18(15.7 \%)$ & $97(84.8 \%)$ & & \\
\hline 3 & $301(65.7 \%)$ & $100(33.2 \%)$ & $201(66.8 \%)$ & & \\
\hline 4 & $39(8.5 \%)$ & $18(46.2 \%)$ & $21(53.6 \%)$ & & \\
\hline 5 & $3(0.7 \%)$ & $2(66.7 \%)$ & $1(33.3 \%)$ & & \\
\hline
\end{tabular}

*Patients with complete information.

Significant $\mathrm{p}$-values in bold. 
Table 2 Baseline characteristics of $\mathbf{4 7 9}$ patients with AF-associated FE-IS and TIA (risk factors and treatment) Variable $\left(\mathbf{N}^{*}\right)$ Death within 500 days Survival of 500 days $p$-value univariate p-value multivariate N (\%)

\section{Risk factors}

\begin{tabular}{|c|c|c|c|c|c|}
\hline $\operatorname{CAD}(465 * / 479)$ & $144(31 \%)$ & $54(37.5 \%)$ & $90(62.5 \%)$ & $p=0.02$ & $p=0.01$ \\
\hline Ml $(475 * / 479)$ & $84(17.7 \%)$ & $33(39.3 \%)$ & $51(60.7 \%)$ & $p=0.07$ & \\
\hline Heart failure $\left(452^{*} / 479\right)$ & $169(37.4 \%)$ & $62(36.7 \%)$ & $107(63.3 \%)$ & $p=0.01$ & $p=0.94$ \\
\hline $\operatorname{PAD}(461 * / 479)$ & $48(10.4 \%)$ & $23(47.9 \%)$ & $25(52.1 \%)$ & $p=0.004$ & $p=0.13$ \\
\hline Hypertension (479*/479) & $446(93.1 \%)$ & $136(30.5 \%)$ & $310(69.5 \%)$ & $p=0.70$ & \\
\hline Diabetes $\left(478^{*} / 479\right)$ & $157(32.8 \%)$ & $43(27.4 \%)$ & $114(72.6 \%)$ & $p=0.34$ & \\
\hline Hypercholesterolemia $\left(470^{*} / 479\right)$ & $285(60.6 \%)$ & $79(27.7 \%)$ & $206(72.3 \%)$ & $p=0.26$ & \\
\hline Smoking $\left(400^{*} / 479\right)$ & & & & $p=0.24$ & \\
\hline Nonsmoker & $206(51.5 \%)$ & $69(33.5 \%)$ & $137(66.5 \%)$ & & \\
\hline Smoker & $42(10.5 \%)$ & $11(26.2 \%)$ & $31(73.8 \%)$ & & \\
\hline Former smoker & $152(38 \%)$ & $39(25.7 \%)$ & $113(74.3 \%)$ & & \\
\hline GFR $(461 * / 479)$ & & & & $\mathrm{p}<0.0001$ & $p=0.09$ \\
\hline $0-<30$ & $16(3.5 \%)$ & $8(50 \%)$ & $8(50 \%)$ & & \\
\hline $30-<60$ & $160(34.7 \%)$ & $66(41.3 \%)$ & $94(58.7 \%)$ & & \\
\hline$\geq 60$ & $285(61.8 \%)$ & $65(22.8 \%)$ & $220(77.2 \%)$ & & \\
\hline \multicolumn{6}{|l|}{ Treatment $(479 * / 479)$} \\
\hline Intraveneous thrombolysis & & & & $p=0.62$ & \\
\hline Yes & $47(9.8 \%)$ & $16(34 \%)$ & $31(66 \%)$ & & \\
\hline No & $432(90.2)$ & $131(30.3)$ & $301(69.7)$ & & \\
\hline \multicolumn{6}{|l|}{ Antithrombotic treatment $(479 * / 479)$} \\
\hline OAK prior to stroke & $116(24.2 \%)$ & $20(17.2 \%)$ & $96(82.8 \%)$ & $p=0.0003$ & $p=0.91$ \\
\hline INR $<2$ & $65(58 \%)$ & $15(23.1 \%)$ & $50(76.9 \%)$ & & \\
\hline$I N R \geq 2$ & $44(39.3 \%)$ & $4(9.1 \%)$ & $40(90.9 \%)$ & & \\
\hline INR unknown & $7(6 \%)$ & $1(14.3 \%)$ & $6(85.7 \%)$ & & \\
\hline Antiplatelets prior to stroke $(479 * / 479)$ & & & & $\mathrm{p}<0.0001$ & \\
\hline No antiplatelet & $298(62.2 \%)$ & $69(23.2 \%)$ & $229(76.8 \%)$ & & \\
\hline Antiplatelet & 181(37.8\%) & $78(43.1 \%)$ & $103(56.9 \%)$ & & \\
\hline OAC management post stroke $(479 * / 479)$ & & & & $\mathrm{p}<0.0001$ & $\mathrm{p}<0.0001$ \\
\hline No VKA & $200(41.8 \%)$ & $127(63.5 \%)$ & $73(37.5 \%)$ & & \\
\hline OAC neither given, nor recommended & $158(79 \%)$ & $109(69 \%)$ & 49 (31\%) & & \\
\hline OAC recommended, but not given & $42(21 \%)$ & $18(42.9 \%)$ & $24(57.1 \%)$ & & \\
\hline VKA started in hospital & $181(37.8 \%)$ & $16(8.8 \%)$ & $165(91.2 \%)$ & & \\
\hline VKA started post discharge & $71(14.8 \%)$ & $2(2.8 \%)$ & $69(97.2 \%)$ & & \\
\hline Unknown & $27(5.6 \%)$ & $2(7.4 \%)$ & $25(93.6 \%)$ & & \\
\hline Recurrent cerebral event (500days) & $43 / 479(9 \%)$ & $21(48.8 \%)$ & $22(51.2 \%)$ & $p=0.009$ & $p=0.27$ \\
\hline IS & $33(76.7 \%)$ & $19(57.6 \%)$ & $14(42.4 \%)$ & & \\
\hline $\mathrm{TIA}$ & $6(14 \%)$ & 0 & 6 & & \\
\hline $\mathrm{ICH}$ & $4(9.3 \%)$ & $2(50 \%)$ & $2(50 \%)$ & & \\
\hline
\end{tabular}

*Patients with complete information. Significant $\mathrm{p}$-values in bold. 
post discharge; 4. Unknown. If OAC was started in hospital or recommended and status post hospital was unknown, OAC management post stroke was ascertained unknown. If VKA treatment had not been recommended, reasons were protocolled. Posthospital treatment with VKA after 30 days, as well as 3, 12 and 36 month after stroke were checked. In order to include majority of patients in univariate and multivariate Cox regression analysis, vital status was additionally assessed 500 days after stroke onset. Recurrent stroke, TIA or bleeding were documented within 500 days after stroke.

\section{Statistical analyses}

$X^{2}$-test was used to compare categorical data and fisher exact test was applied to analyse normally distributed continuous data in univariate analysis. All variables being significant except risk stratification scores were then included in a multivariate Cox regression model followed by backward elimination of nonsignificant variables $(\mathrm{p}<$ $0,05)$. In order to lower impact of stroke severity on stroke mortality, patients who died within 7 days after stroke were excluded for multivariate Cox regression analysis. All data were analysed using SAS 9.3 software (SAS Institute, North Carolina, RRID:nif-0000-31484). All tests were two-sided. Level of significance was set to $5 \%$ for all tests.

\section{Results}

During study period, 502 patients had a FEIS or TIA due to AF. ICH was ruled out in all patients by neuroimaging. As survival status was unknown in 23 patients (4.8\%), 479 patients with FEIS $(\mathrm{n}=394)$ and TIA $(\mathrm{n}=85)$ were finally included in the present analysis. Mean age was 79.3 years $+/-$ 10.1 (women: 80.7 years $+/-10.5$; men: 77.4 years $+/-9.1$ ). Median of hospital stay was 10.8 days (range 1-35 days). 332 patients $(69.3 \%)$ were initially admitted to a stroke unit, whereas 29 patients $(6.1 \%)$ received intensive care treatment. Overall, 18 patients $(3.8 \%)$ were treated ambulatory. Thirteen patients died within first week. One year mortality rate was $28.4 \%$ and mortality rate after 500 days was $30.7 \%$.

Neuroimaging was performed in all patients with 106 patients (22.1\%) receiving cranial MRI. AF was newly diagnosed in $62(12.9 \%)$ patients. Acute ischemic tissue damage could be observed in 20 patients $(23.5 \%)$ with TIA based on neuroimaging. Due to study period, no patient received NOAC treatment. Baseline characteristics of all patients are displayed in Tables 1 and 2. Overall, OAC with VKA was started in hospital in 184 patients and it was continued post hospital in 181 patients (98.4\%). Starting OAC post discharge was recommended in total in 130 patients. In 20 out of these patients OAC status post discharge was unknown and OAC-recommendation was implemented in 71 patients (64.5\%). Figure 1 shows KaplanMeier estimate of survival after ischemic stroke according to OAC management. Antiplatelet therapy was prescribed in $173(36.1 \%)$ patients. There was no patient who received a combination of OAC and antiplatelet agent. Main reasons for non-OAC recommendation were bad general condition $(28 \%, \mathrm{n}=41)$, risk of falling $(27 \%, \mathrm{n}=39)$ and

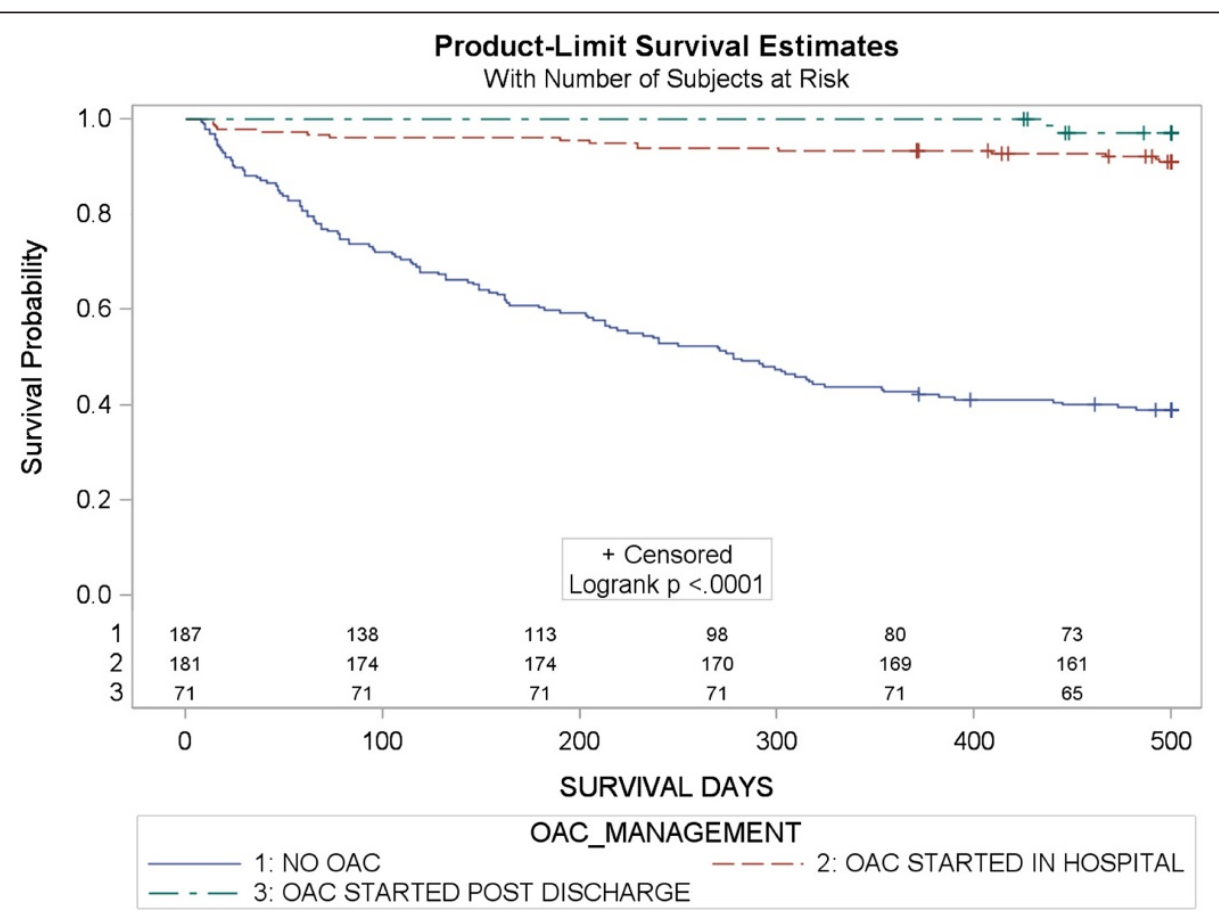

Figure 1 Kaplan-Meier estimate of survival after ischemic stroke according to OAC management $((n=439)$ patients who died within 7 days $(n=13)$ excluded). 
Table 3 Multivariate Cox regression analysis

\begin{tabular}{lll}
\hline Variable & HR (95\% Cl) & P-value \\
\hline Model $\boldsymbol{A} \boldsymbol{n}=\mathbf{3 9 7}$ (90.4\%) & $1.04(1.02-1.07)$ & $\mathbf{p}=\mathbf{0 . 0 0 1}$ \\
Age (per year) & $1.6(1.1-2.3)$ & $\mathbf{p}=\mathbf{0 . 0 1}$ \\
CAD (Yes vs. No) & $1.2(1.1-1.4)$ & $\mathbf{p}=\mathbf{0 . 0 0 0 7}$ \\
mRS at discharge (per year) & & \\
OAK management post stroke & & $\mathbf{p}<\mathbf{0 . 0 0 0 1}$ \\
(VKA in hospital as reference) & $5.4(2.8-10.5)$ & $\mathbf{p}=\mathbf{0 . 1}$ \\
No VKA & $0.3(0.07-1.4)$ &
\end{tabular}

Significant $p$-values in bold.

dementia $(13 \%, n=19)$. As compared to those patients with recommendation to start OAC treatment post discharge, patients receiving OAC treatment in hospital had signficant lower initial stroke severity as indicated by NIHSS ( $p>0.0001)$, lower HASBLED-score $(\mathrm{p}=0.001)$, less signs of hemorrhagic transformation $(p=0.002)$ and territorial infarction $(p>0.0001)$, high rate of premedication with VKA ( $p<0.0001)$, low rate of premedication with antiplatelets $(\mathrm{p}<0.0001)$ and significant lower $\mathrm{mRS}$-score $(\mathrm{p}<0.0001)$ on discharge. Recurrent stroke within 500 days occurred in 43 patients (9\%) with 13 patients $(30,2 \%)$ being on OAC (started in hospital: $\mathrm{n}=8(61.5 \%)$ vs. started post discharge: $\mathrm{n}=5$ (38.5\%), of which 6 patients (46.1\%) had an INR-value below 2. Three out of 5 patients (60\%) with OAC having an INR $>2$, had a recurrent ischemic stroke within 30 days after OAC. One year recurrence rate was $7.1 \%(n=34)$, whereas rate of early stroke recurrence within 14 days was $0.8 \%(\mathrm{n}=4)$ and within 7 days $0.4 \%$ $(\mathrm{n}=2)$. OAC associated $\mathrm{ICH}$ was observed in three patients $(0.6 \%)$, two $(66.7 \%)$ occuring within 30 days after initial event.

Results of Cox regression analysis are displayed in Table 3. Higher age, higher mRS-score at discharge, diagnosis of $\mathrm{CAD}$, and $\mathrm{OAC}$ treatment post stroke were independently associated with stroke mortality. Figure 2 additionally presents Kaplan-Meier estimate of survival with regard to stroke recurrence. Poststroke survival was highest in those patients receiving $\mathrm{OAC}$ irrespective of stroke recurrence.

\section{Discussion}

We analysed impact of risk factors on mortality (500 days) in patients after first ever AF-associated CES or TIA in a population based stroke registry (LuSSt) particulary with regards to the effect of different OAC timings after FEIS. One-year mortality rate was $28.4 \%$, which is in line with former study reports, where patients having a stroke associated with AF had a high risk of death in the year after FEIS [21].

Our data show that OAC non-treatment after AFassociated ischemic stroke is the main predictor for stroke mortality. Mortality was 5.4 times higher in patients not receiving $\mathrm{OAC}$ as compared to those that already received OAC in hospital. This fact again underlines the need for OAC treatment after CES [22]. Alarmingly, OAC-recommendation was only implemented in 71 out of 110 patients calling for improvement in outpatient care (e.g. by the implementation of special

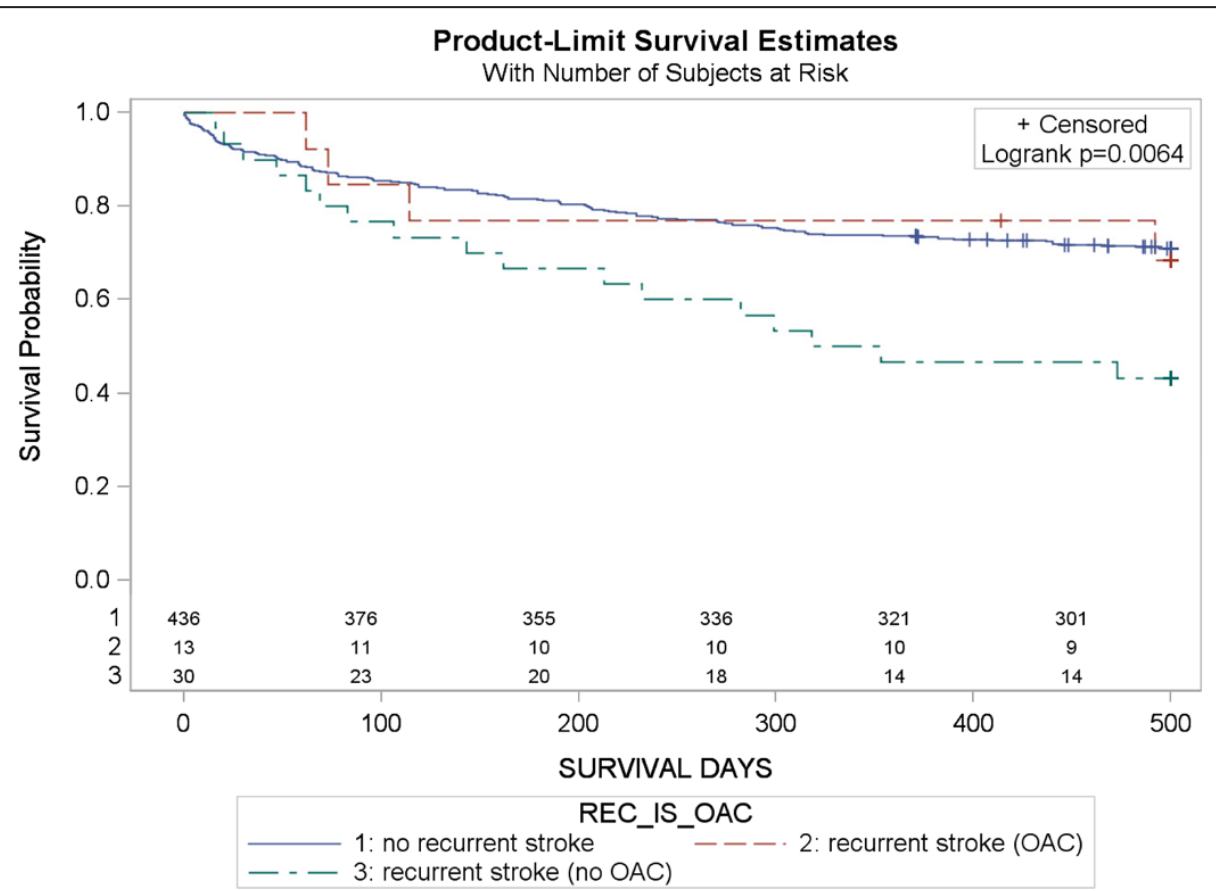

Figure 2 Kaplan-Meier estimate of survival after ischemic stroke according to recurrence of stroke on and off OAC treatment ( $n=479)$. 
interventional programs) [23]. Interestingly, OAC initiation post discharge showed a trend $(\mathrm{p}=0.1)$ towards lower mortality as compared to those that received OAC in hospital (HR 0.3; 95\% CI 0.07-1.4) in multivariate analysis. Increased risk of bleeding under early treatment with OAC in more severe strokes might be one explanation [24]. Increased risk of ischemic stroke during first 30 days of treatment might also partly account for this [25]. In addition to OAC treatment, we found higher age and a higher mRS-score at discharge as independent predictors of mortality after CES. Recent data from the Canadian Stroke Network demonstrated association between older age and worse outcome after CES. Interestingly, there was no such association in those patients receiving therapeutic OAC treatment prior to stroke emphasizing the importance of OAC treatment in older patients [26]. It is well known that myocardial infarction is the leading cause of death in patients with cerebrovascular diseases [27]. We found CAD to be independently associated with mortality after CES. Antiplatelet agents such as Aspirin or Clopidogrel have shown to reduce ischemic events in patients with CAD [28]. Unfortunately, concomitant use of antiplatelet agents and OAC subsequently increases risk of bleeding [29]. Randomized trials have shown VKA to be as effective as a combination of VKA and Aspirin and more effective as Aspirin alone in CAD patients considering myocardial infarction [30]. Although recent observational studies showed decreased rate of $\mathrm{MI}$ in AF patients receiving Dabigatran as compared to Warfarin [31], certain subgroup analyses and metanalyses of randomized controlled trials demonstrated an increase of myocardial infarction [32,33]. However, data of endpoint driven randomized controlled trials on NOACs are missing. Right now, OAC with VKA might remain important for CES patients having CAD. Recurrence rates were similar to those reported in previous trials [34,35]. Although being limited by small sample size, stroke recurrence did not influence survival in those patients receiving $\mathrm{OAC}$, whereas there was a clear interaction in those patients that did not receive OAC. Clinical benefit of OAC in AF is again underlined.

Our study has strengths and limitations. Being based on registry data, study design was primarily descriptive and besides other confounding factors, quality of treatment of risk factors was not implemented, especially considering time of therapeutic range of VKA treatment. Furthermore we only analysed all-cause mortality. However, LuSSt is a population-based stroke registry without any age restrictions. Multiple overlapping methods were used to ensure nearly complete case ascertainment and high case completeness was achieved with regard to stroke mortality.

\section{Conclusion}

In our study OAC non-treatment was the main predictor for mortality after FEIS. A later initiation of OAC treatment post hospital was not inferior to early initiation during hospital stay, however, one third of those patients who were recommended to be treated with OACs never received treatment. Special secondary preventive programs may increase the proportion of anticoagulated patients after stroke due to AF.

\section{Competing interests}

The authors declare that they have no competing interests.

\section{Authors' contributions}

All authors have made substantive intellectual contributions to this study. FP and MK have made substantial contributions to data acquisation, data analysis and data interpretation. AS and HB substantially contributed to data analysis and interpretation. AG was responsible for study conception and design as well as data interpretation. All authors critically drafted and revised the manuscript. They all agree to be accountable for all aspects of the work in ensuring that questions related to the accuracy or integrity of any part of the work are appropriately investigated and resolved. All authors read and approved the final manuscript.

\section{Acknowledgements}

We gratefully acknowledge the very valuable help by Susanne Streib who participated as study nurse in this study.

\section{Funding}

Data analysis and data acquisition (AG, HB, AS, FP) was supported by a grant from the Deutsche Forschungsgemeinschaft (DFG; GR1102/6-1). Study design, data collection, data analysis and data interpretation were independent from any study sponsor. LuSSt is part of the German Competence Network Stroke.

\section{Author details}

${ }^{1}$ Department of Neurology, Städtisches Klinikum Ludwigshafen, Bremserstr. 79, 67063 Ludwigshafen, Germany. ${ }^{2}$ Department of Internal Medicine, Klinikum, Ludwigshafen, Germany. ${ }^{3}$ Institute of Public Health,

Universitätsklinikum Heidelberg, Heidelberg, Germany.

Received: 27 May 2014 Accepted: 25 September 2014

Published online: 08 October 2014

\section{References}

1. Hajat C, Heuschmann PU, Coshall C, Padayachee S, Chambers J, Rudd AG, Wolfe CD: Incidence of aetiological subtypes of stroke in a multi-ethnic population based study: the south London stroke register. J Neurol Neurosurg Psychiatry 2011, 82(5):527-533.

2. Palm F, Urbanek C, Wolf J, Buggle F, Kleemann T, Hennerici MG, Inselmann G, Hagar M, Safer A, Becher H, Grau AJ: Etiology, risk factors and sex-differences in ischemic stroke in the Ludwigshafen stroke study (LuSSt), a populationbased stroke registry. Cerebrovasc Dis 2012, 33(1):64-68.

3. Jickling GC, Stamova B, Ander BP, Zhan X, Liu D, Sison SM, Verro P, Sharp FR: Prediction of cardioembolic, arterial, and lacunar causes of cryptogenic stroke by gene expression and infarct location. Stroke 2012, 43(8):2036-2041.

4. Lloyd-Jones DM, Wang TJ, Leip EP, Larson MG, Levy D, Vasan RS, D'Agostino RB, Massaro JM, Beiser A, Wolf PA, Benjamin EJ: Lifetime risk for development of atrial fibrillation: the framingham heart study. Circulation 2004, 110(9):1042-1046

5. Naccarelli GV, Varker H, Lin J, Schulman KL: Increasing prevalence of atrial fibrillation and flutter in the United States. Am J Cardiol 2009, 104(11):1534-1539.

6. Hannon N, Sheehan O, Kelly L, Marnane M, Merwick A, Moore A, Kyne L, Duggan J, Moroney J, McCormack PM, Daly L, Fitz-Simon N, Harris D, Horgan G, Williams EB, Furie KL, Kelly PJ: Stroke associated with atrial fibrillation-incidence and early outcomes in the north Dublin population stroke study. Cerebrovasc Dis 2010, 29(1):43-49.

7. Kolominsky-Rabas PL, Weber M, Gefeller O, Neundoerfer B, Heuschmann PU: Epidemiology of ischemic stroke subtypes according to TOAST criteria: incidence, recurrence, and long-term survival in ischemic stroke subtypes: a population-based study. Stroke 2001, 32(12):2735-2740. 
8. Grau AJ, Weimar C, Buggle F, Heinrich A, Goertler M, Neumaier S, Glahn J, Brandt T, Hacke W, Diener HC: Risk factors, outcome, and treatment in subtypes of ischemic stroke: the German stroke data bank. Stroke 2001, 32(11):2559-2566.

9. Agarwal S, Hachamovitch R, Menon V: Current trial-associated outcomes with warfarin in prevention of stroke in patients with nonvalvular atrial fibrillation: a meta-analysis. Arch Intern Med 2012, 172(8):623-631. discussion 631-623.

10. Ntaios G, Papavasileiou V, Diener HC, Makaritsis K, Michel P: Nonvitamin-Kantagonist oral anticoagulants in patients with atrial fibrillation and previous stroke or transient ischemic attack: a systematic review and meta-analysis of randomized controlled trials. Stroke 2012, 43(12):3298-3304.

11. Lip GY, Andreotti F, Fauchier L, Huber K, Hylek E, Knight E, Lane D, Levi M, Marin F, Palareti G, Kirchhof P: Bleeding risk assessment and management in atrial fibrillation patients. Executive summary of a position document from the European heart rhythm association [EHRA], endorsed by the european society of cardiology [ESC] working group on thrombosis. Thromb Haemost 2011, 106(6):997-1011.

12. Paciaroni M, Agnelli G, Corea F, Ageno W, Alberti A, Lanari A, Caso V, Micheli S, Bertolani L, Venti M, Palmerini F, Biagini S, Comi G, Previdi P, Silvestrelli G: Early hemorrhagic transformation of brain infarction: rate, predictive factors, and influence on clinical outcome: results of a prospective multicenter study. Stroke 2008, 39(8):2249-2256.

13. McGrath ER, Kapral MK, Fang J, Eikelboom JW, O'Conghaile A, Canavan M, O'Donnell MJ: Which risk factors are more associated with ischemic stroke than intracerebral hemorrhage in patients with atrial fibrillation? Stroke 2012, 43(8):2048-2054.

14. Palm F, Urbanek C, Rose S, Buggle F, Bode B, Hennerici MG, Schmieder K, Inselmann G, Reiter R, Fleischer R, Piplack KO, Safer A, Becher H, Grau AJ: Stroke incidence and survival in ludwigshafen am rhein, Germany: the Ludwigshafen stroke study (LuSSt). Stroke 2010, 41(9):1865-1870.

15. Hatano S: Experience from a multicentre stroke register: a preliminary report. Bull World Health Organ 1976, 54(5):541-553.

16. Camm AJ, Kirchhof P, Lip GY, Schotten U, Savelieva I, Ernst S, Van Gelder IC, Al-Attar N, Hindricks G, Prendergast B, Heidbuchel H, Alfieri O, Angelini A, Atar D, Colonna P, De Caterina R, De Sutter J, Goette A, Gorenek B, Heldal M, Hohloser SH, Kolh P, Le Heuzey JY, Ponikowski P, Rutten FH: Guidelines for the management of atrial fibrillation: the task force for the management of atrial fibrillation of the european society of cardiology (ESC). Eur Heart $J$ 2010, 31(19):2369-2429

17. Camm AJ, Lip GY, De Caterina R, Savelieva I, Atar D, Hohnloser SH, Hindricks G, Kirchhof P: 2012 focused update of the ESC guidelines for the management of atrial fibrillation: an update of the 2010 ESC guidelines for the management of atrial fibrillation. Developed with the special contribution of the European heart rhythm association. Eur Heart $\lrcorner$ 2012, 33(21):2719-2747.

18. Banks $\lrcorner$, Marotta CA: Outcomes validity and reliability of the modified rankin scale: implications for stroke clinical trials: a literature review and synthesis. Stroke 2007, 38(3):1091-1096.

19. Goldstein LB, Bertels C, Davis JN: Interrater reliability of the NIH stroke scale. Arch Neurol 1989, 46(6):660-662

20. Levey AS, Coresh J, Balk E, Kausz AT, Levin A, Steffes MW, Hogg RJ, Perrone RD, Lau J, Eknoyan G: National kidney foundation practice guidelines for chronic kidney disease: evaluation, classification, and stratification. Ann Intern Med 2003, 139(2):137-147.

21. Kaarisalo MM, Immonen-Raiha P, Marttila RJ, Salomaa V, Kaarsalo E, Salmi K, Sarti C, Sivenius J, Torppa J, Tuomilehto J: Atrial fibrillation and stroke. Mortality and causes of death after the first acute ischemic stroke. Stroke 1997, 28(2):311-315.

22. Andersen KK, Olsen TS: Reduced poststroke mortality in patients with stroke and atrial fibrillation treated with anticoagulants: results from a danish quality-control registry of 22,179 patients with ischemic stroke. Stroke 2007, 38(2):259-263.

23. Leistner S, Benik S, Laumeier I, Ziegler A, Nieweler G, Nolte CH, Heuschmann PU, Audebert $\mathrm{HJ}$ : Secondary prevention after minor stroke and TIA - usual care and development of a support program. PLoS One 2012, 7(12):e49985.

24. Fang MC, Go AS, Chang Y, Borowsky LH, Pomernacki NK, Udaltsova N, Singer DE: Thirty-day mortality after ischemic stroke and intracranial hemorrhage in patients with atrial fibrillation on and off anticoagulants. Stroke 2012, 43(7):1795-1799.
25. Azoulay L, Dell'aniello S, Simon TA, Renoux C, Suissa S: Initiation of warfarin in patients with atrial fibrillation: early effects on ischaemic strokes. Eur Heart J 2014, 35(28):1991-1887.

26. McGrath ER, Kapral MK, Fang J, Eikelboom JW, O'Conghaile A, Canavan M, O'Donnell MJ: Association of atrial fibrillation with mortality and disability after ischemic stroke. Neurology 2013, 81(9):825-832.

27. Heyden S, Heiss G, Heyman A, Tyroler AH, Hames CG, Patzschke U, Manegold C: Cardiovascular mortality in transient ischemic attacks. Stroke 1980, 11(3):252-255

28. Clappers N, Brouwer MA, Verheugt FW: Antiplatelet treatment for coronary heart disease. Heart 2007, 93(2):258-265.

29. Sorensen R, Hansen ML, Abildstrom SZ, Hvelplund A, Andersson C, Jorgensen C, Madsen JK, Hansen PR, Kober L, Torp-Pedersen C, Gislason GH: Risk of bleeding in patients with acute myocardial infarction treated with different combinations of aspirin, clopidogrel, and vitamin $\mathrm{K}$ antagonists in Denmark: a retrospective analysis of nationwide registry data. Lancet 2009, 374(9706):1967-1974.

30. van Es RF, Jonker JJ, Verheugt FW, Deckers JW, Grobbee DE: Aspirin and coumadin after acute coronary syndromes (the ASPECT-2 study): a randomised controlled trial. Lancet 2002, 360(9327):109-113.

31. Larsen TB, Rasmussen LH, Skjoth F, Due KM, Callreus T, Rosenzweig M, Lip GY: Efficacy and safety of dabigatran etexilate and warfarin in "real-world" patients with atrial fibrillation: a prospective nationwide cohort study. J Am Coll Cardiol 2013, 61(22):2264-2273.

32. Oldgren J, Budaj A, Granger CB, Khder Y, Roberts J, Siegbahn A, Tijssen JG, Van de Werf F, Wallentin L: Dabigatran vs. placebo in patients with acute coronary syndromes on dual antiplatelet therapy: a randomized, double-blind, phase II trial. Eur Heart J 2011, 32(22):2781-2789.

33. Uchino K, Hernandez AV: Dabigatran association with higher risk of acute coronary events: meta-analysis of noninferiority randomized controlled trials. Arch Intern Med 2012, 172(5):397-402.

34. Secondary prevention in non-rheumatic atrial fibrillation after transient ischaemic attack or minor stroke: EAFT (european atrial fibrillation trial) study group. Lancet 1993, 342(8882):1255-1262.

35. Diener HC, Eikelboom J, Connolly SJ, Joyner CD, Hart RG, Lip GY, O'Donnell M, Hohnloser SH, Hankey GJ, Shestakovska O, Yusuf S: Apixaban versus aspirin in patients with atrial fibrillation and previous stroke or transient ischaemic attack: a predefined subgroup analysis from AVERROES, a randomised trial. Lancet Neurol 2012, 11(3):225-231.

doi:10.1186/s12883-014-0199-7

Cite this article as: Palm et al:: Management of oral anticoagulation after cardioembolic stroke and stroke survival data from a population based stroke registry (LuSSt). BMC Neurology 2014 14:199.

\section{Submit your next manuscript to BioMed Central and take full advantage of:}

- Convenient online submission

- Thorough peer review

- No space constraints or color figure charges

- Immediate publication on acceptance

- Inclusion in PubMed, CAS, Scopus and Google Scholar

- Research which is freely available for redistribution 